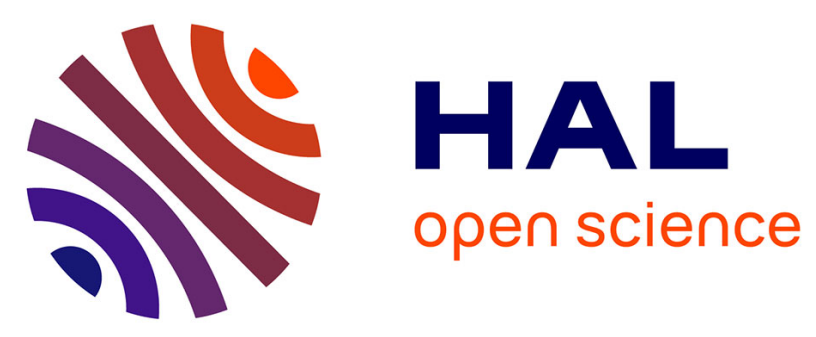

\title{
Inhomogeneous tumor dose distribution provides better local control than homogeneous distribution in stereotactic radiotherapy for brain metastases
}

François Lucia, Stéphane Key, Gurvan Dissaux, Gaëlle Goasduff, Anne-Sophie Lucia, Luc Ollivier, Olivier Pradier, Ulrike Schick

\section{To cite this version:}

François Lucia, Stéphane Key, Gurvan Dissaux, Gaëlle Goasduff, Anne-Sophie Lucia, et al.. Inhomogeneous tumor dose distribution provides better local control than homogeneous distribution in stereotactic radiotherapy for brain metastases. Radiotherapy \& Oncology, 2019, 130, pp.132 - 138. 10.1016/j.radonc.2018.06.039 . hal-03484623

\section{HAL Id: hal-03484623 \\ https://hal.science/hal-03484623}

Submitted on 20 Dec 2021

HAL is a multi-disciplinary open access archive for the deposit and dissemination of scientific research documents, whether they are published or not. The documents may come from teaching and research institutions in France or abroad, or from public or private research centers.
L'archive ouverte pluridisciplinaire HAL, est destinée au dépôt et à la diffusion de documents scientifiques de niveau recherche, publiés ou non, émanant des établissements d'enseignement et de recherche français ou étrangers, des laboratoires publics ou privés.

\section{(c) (1) $\$$}

Distributed under a Creative Commons Attribution - NonCommerciall 4.0 International 
Inhomogeneous tumor dose distribution provides better local control than homogeneous distribution in stereotactic radiotherapy for brain metastases

\section{François Lucia ${ }^{1,2}$, Stéphane Key ${ }^{1}$, Gurvan Dissaux ${ }^{1}$, Goasduff Gaëlle ${ }^{1}$, Lucia Anne-Sophie ${ }^{1}$, Luc Olivier ${ }^{1}$, Olivier Pradier ${ }^{1,2}$, Ulrike Schick*1,2}

1. Radiation Oncology department, University Hospital, Brest, France

2. LaTIM, INSERM, UMR 1101, University of Brest, ISBAM, UBO, UBL, Brest, France

Corresponding author: François Lucia

Service de radiothérapie

CHRU Morvan, 2 avenue Foch

29609 Cedex, Brest, France

Tel: +33699740318

E-mail: francois.lucia@gmail.com

Wordcount: 2700

Disclosure of Conflicts of Interest: No potential conflicts of interest were disclosed. 


\section{Inhomogeneous tumor dose distribution provides better local control than homogeneous distribution in stereotactic radiotherapy for brain metastases.}

\section{Highlights}

The most important manuscript's points are highlighted below:

$>$ Question: SRT technologies use different dose prescription modalities, so there is no consensus and a high variability in dose prescription between teams and center exists.

Findings:

$>\mathrm{SRT}$ delivered with inhomogeneous dose distribution resulted in better LC compared to homogeneous dose distribution

$>$ SRT delivered with inhomogeneous dose distribution resulted in lower RN rate compared to homogeneous dose distribution

Meaning

These results support the recommendations of the ICRU report 91 to use inhomogeneous dose distribution with a high dose in the middle of the target

\section{INTRODUCTION:}

The aim of this study was to analyze the impact of inhomogeneous versus homogeneous dose distribution on local control (LC) and radionecrosis (RN) in patients treated with fractionated stereotactic radiotherapy (SRT) for newly-diagnosed brain metastases (BM).

\section{PATIENTS AND METHODS:}

From 2014 to 2017, 134 patients (median age 61 years) underwent SRT for BM ( $n=114$ with $\leq 2, n=20$ with 3-6 BM) at our institution. Treatment was delivered using volumetric modulated arc therapy on a linear accelerator. Ninety-one consecutive patients $(B M=136)$ were irradiated at a dose of 21$23.1 \mathrm{~Gy}$ in 3 fractions delivered homogeneously (99\% of the dose had to cover $99 \%$ of the planning target volume (PTV)) (group 1) whereas the following 43 patients (BM=72) received an inhomogeneous dose of 10 or $11 \mathrm{~Gy}$ prescribed to the isocenter with the $70 \%$ isodose line covering the PTV (group 2). Variables analyzed included dose distribution, age, gender, histology, diagnosisspecific Graded Prognostic Assessment score, number of brain metastases, presence of extracranial metastases, and tumor volumes.

\section{RESULTS:}

After a median follow-up of 12.4 months (range, 1.4-33.1), the 1-year LC and RN rate were $78 \%$ and $7.5 \%$ in group 1 and $93 \%$ and $0 \%$ in group 2 , respectively ( $p=0.005)$. In multivariate analysis, improved LC was significantly correlated with SRT dose distribution $(p=0.009)$ and tumor volume $(p=0.03)$. The number of metastases $(p=0.03)$ and SRT dose distribution $(p=0.04)$ were both associated with increased risk of RN.

\section{CONCLUSION:}

SRT delivered with inhomogeneous dose distribution resulted in better LC and a lower risk of $\mathrm{RN}$ compared to homogeneous distribution. 


\section{INTRODUCTION}

It is estimated that $20 \%$ to $40 \%$ of cancer patients will develop brain metastases (BMs) during the course of their illness [1]. Alongside with whole brain radiotherapy, systemic treatments and surgery, the role of stereotactic radiosurgery (SRS) or fractionation stereotactic radiotherapy (SRT) for local control (LC) improvement is now well recognized [2]. In particular, SRS/SRT approaches can be recommended in patients having 1-4 BMs and a life expectancy of more than 3-6 months $[3,4]$. Recently, SRT has been preferred over whole-brain radiotherapy (WBRT) in order to maximize local control while minimizing the probability of neurocognitive dysfunctions $[5,6]$.

SRT requires a high accuracy, a very steep dose gradient and a high level of conformity to ensure tumor coverage and protection of the surrounding tissues. Historically, as the SRT technique used fixed circular collimators, the dose prescription has been using the so-called "coverage isodoses" to represent some form of minimum target dose [7-9]. However, for a target volume, the median absorbed dose is close to the mean absorbed dose in intensity modulated radiotherapy (IMRT)(and should be as close as possible to the near minimum dose D98\% so as to achieve dose homogeneity) [10]. However in SRT, there is generally much less normal tissue within the planning target volume (PTV) and there may be critical normal tissues very close to the target volume. Hence, the treatment of these spatially limited volumes with multiple small photon beams may imply dose heterogeneity to maintain optimal conformity and acceptably steep dose gradients. But, there is no consensus and a high variability in dose prescription between teams and center exists [7, 11].

The main goal of this study was to compare LC and toxicity between two volumetric modulated arc therapy (VMAT) dosimetric plans using either low or high homogeneity in SRT for BM.

\section{MATERIALS AND METHODS}

\section{Patients' selection}

Patients treated using SRT for BMs from 12/2014 to 05/2017 at our institution were considered in this study. SRT was suggested at multidisciplinary team meetings, which included a radiation oncologist, a neurosurgeon, a medical oncologist, and a neuroradiologist. Patients were offered SRT if the following criteria were met: (a) non critical anatomic position, (b) absence of acute neurological symptoms, (c) life expectancy $>3$ months according to Diagnosis-Specific Graded Prognostic Assessment (DS-GPA), (d) number of brain metastases $\leq 6$, (e) and larger diameter $<40 \mathrm{~mm}$ according to magnetic resonance imaging (MRI). Patients were excluded when the SRS was given to surgical cavity.

The MRI examination done for diagnosis and treatment decision included Fluid-attenuated inversion recovery (FLAIR) sequence and T1 weighted sequence. Thoraco-abdomino-pelvic computed tomography (CT) with contrast enhancement or 18F-fluorodeoxyglucose (FDG) positron emission tomography/computed tomography (PET/CT) was performed in all patients to define the extracranial disease status which was defined as no evidence of disease or decreased/stable burden or progressive disease outside the central nervous system.

All patients provided signed permission for the use of their clinical data for scientific purposes and informed consent for the anonymous publication of data. Institutional Review Board approved this study. 


\section{Imaging and delineation}

Planning CT (Philips, Somatom) was obtained with a $1.5 \mathrm{~mm}$ slice thickness. Patients were immobilized with a frameless thermoplastic mask (BrainLAB ${ }^{\circledR}$, Feldkirchen, Germany). A coregistration of volumetric $\mathrm{CT}$ and MRI-T1 sequences, typically a 3-dimensional spoiled gradient series with 1-mm slice thickness performed within the last two weeks before SRT, was used to define target and organs at risk (OARs). Gross tumor volume (GTV) was defined as macroscopic contrast enhancing lesion on T1-MRI and was equal to clinical target volume (CTV). PTV was obtained by adding an isotropic margin of $2 \mathrm{~mm}$ in all directions. OARs included brain, normal brain minus PTV, eyes, lens, optic chiasm, optic nerves, brainstem, and spinal cord.

\section{Treatment planning}

A total dose of 21 or 23.1 Gy in 3 fractions was prescribed at the PTV periphery, according to different clinical and radiological parameters including BM size, presence of subacute or acute neurological symptoms, proximity to OARs, and critical anatomical position.

Treatment plans were generated for a TrueBeamTM STX linac (Varian Medical Systems, Palo Alto, CA) equipped with standard Millennium MultiLeaf Collimator (MLC) with 120 leaves (thickness of $2.5 \mathrm{~mm}$ at isocenter and up to $8 \mathrm{~cm}$ followed by a thickness of $5 \mathrm{~mm}$ from 8 to $22 \mathrm{~cm}$ ). Every patient was planned using a Flattening-Filter (FF) VMAT technique with $6 \mathrm{X}$ beams in the Pinnacle ${ }^{\circledR}$ treatment $^{\circ}$ planning system (Philips, v9.10). We used two arcs from $182^{\circ}$ to $178^{\circ}$ for each VMAT plan. The maximum dose rate was set to $600 \mathrm{MU} / \mathrm{min}$ for $6 \mathrm{X}$ beams.

The prescribed dose (PD) to the PTV was a uniform dose of $3 \times 7.7 \mathrm{~Gy}$ in the periphery of the PTV (99\% isodose line covering $99 \%$ of the PTV) with a maximal dose of $107 \%$ (8.2 Gy) for the first 2 years (group 1). In the following patients (group 2), the planning protocol was modified and a dose gradient was created inside the PTV: the PD was $3 \times 11$ Gy at the isocenter with the $70 \%$ isodose line covering $99 \%$ of the PTV. In both groups, $99 \%$ of PTV received $99 \%$ of the PD ( $3 \times 7.7$ Gy) (figure 2 , supplementary files). When dose constraints to the OAR could not be met, the prescribed dose per fraction was decreased to $7 \mathrm{~Gy}$ and $10 \mathrm{~Gy}$ in each group, respectively.

The dose at the OAR were the following [12]: maximal dose to the optic nerves $<13.8 \mathrm{~Gy}$, maximal dose to the optic chiasm < 10.5 Gy, maximal dose to brainstem <16.8 Gy, and V10Gy and V21Gy of < $5 \%$ and $<20.9 \mathrm{cc}$, respectively.

\section{Outcome evaluation}

Outcomes were evaluated by neurological examination and brain MRI performed 6 weeks following SRT completion and then every 3 months. Radiological response on MRI was assessed by a expert neuroradiologist according to the Response Assessment for Brain Metastases (RANO-BM) criteria [13] : Local control was defined as the absence of new radiographic enhancing abnormality in the irradiated areas on MR imaging, and distant brain metastasis (DBM) as the presence of new brain metastases or leptomeningeal enhancement outside the treated region.

Radionecrosis (RN) was assessed using contrast enhanced T1-I, T2 weighted- and perfusion-MRI. It was considered as the presence of central hypo-density and peripheral enhancement on T1-weighted post-contrast imaging, associated with edema on T2-weighted sequences and a lack of perfusion without any nodular highly vascularized area within the contrast enhanced lesion on perfusion MRI. If multiparametric MRI was inconclusive, a -F-18 fluoroethyltyrosine (FET)-PET was performed [14]. Histological confirmation of RN was not systematically required.

Systemic disease was evaluated by contrast enhanced total body CT scan, and/or 18-FDG CT-PET, depending on the primary disease. 


\section{STATISTICAL METHODS}

Standard descriptive statistics were used to describe the general data behavior. LC was defined from the SRT start to time of the local relapse. Intracranial progression was considered from the SRT start to the time of any new central nervous system progression. Overall survival (OS) was calculated from the date of diagnosis to the death or last follow-up date. In order to investigate the prognostic role of individual variables, the log-rank test or univariate Cox regression were used, respectively, for categorical and numerical data. The receiver operating characteristic (ROC) curve was used to determine cut-off values of significant parameters according to the Youden index. Multivariate Cox model was used as a method to estimate the independent association of a variable set with OS, LC, and brain distant failure (BDF).

Prognostic factors analyzed were age (> or $\leq 57)$, gender, primary tumor, KPS, RPA classes (I-III), updated DS-GPA [15], overall disease control, presence of extracranial metastatic sites at the time of SRT, number of BMs ( $\leq 1$ vs $>1$ ), GTV and PTV volumes, and administration of systemic or targeted therapies after local treatments of BMs. Regarding the tumor volume, the largest GTV and PTV were considered in patients with several irradiated BM. But, the sum of the GTVs (and PTVs) were also calculated and correlated with outcome.

All statistical analyses were performed using MedCalc Statistical Software version 15.8 (MedCalc Software bvba, Ostend, Belgium; https://www.medcalc.org; 2015).

\section{RESULTS}

\section{Patient and tumor characteristics}

Over the considered period, a total of 134 patients presenting with 208 metastases of various histologies were treated with SRT: The first group was treated from 12/2014 to 12/2016 and included 91 patients with a total of 136 metastases. The second group treated from 12/2016 to 05/2017 included 43 patients with a total of 72 metastases.

Both groups had similar clinical, histopathological and treatments' characteristics (table 1) except for dosimetric parameters represented by the D2\% and the D50\% (table 2). As expected these two parameters were higher in group 2: 24.8 versus 32.9 Gy for D2\%, and 24.2 versus 28.1 Gy for D50\% in group 1 and 2 , respectively ( $<<0.0001$ for both parameters). The majority of patients had a KPS $90-$ $100(70 \%)$, were in RPA class II (87.8\%), had lung cancer (65.7\%), and a DS-GPA score 2.5-3 (46.8\%). At the time of BMs diagnosis, $48(35.8 \%)$ patients had also extra-cranial metastases. The majority of patients had $\leq 2 \mathrm{BMs}$ (70.1\%). Mean PTV volume were $5.63 \pm 6.87 \mathrm{~cm}^{3}$.

\section{Local control, distant brain failure and overall survival analysis}

The median follow-up times in group 1 and 2 were 13.1 months (1.4-33.1) and 11.9 months (3.717.3), respectively.

Local failure occurred in 36/208 (17\%) irradiated metastases. The 6-months and 1-year LC rates were $94.9 \pm 1.6 \%$, and $83.3 \pm 3 \%$, respectively. On univariate analysis, factors recorded as influencing LC were dose distribution, tumor volume and D2\%. On multivariate analysis the dose distribution and the tumor volume remained statistically associated with LC (table 3). In group 1, 32/136 (23.5\%) metastases were not controlled locally whereas this was the case for $4 / 72(5.6 \%)$ metastases in group 2. The estimated 1-year LC rates of metastases irradiated with homogeneous versus inhomogeneous dose were $78 \%$ versus $93 \%(p=0.005)$, respectively. Similarly, $92 \%$ and $69 \%$ metastases with low versus high tumor volume were still controlled at one year (cut-off 2.04, $\mathrm{p}<0.0001$ )(figure 1). 
BDF occurred in 37 (28\%) patients and the 1-year freedom from distant brain metastases (FFDBM) rate was $69 \pm 3.6 \%$. On univariate analysis, factors recorded as influencing FFDBM were dose distribution, tumor volume and age. On multivariate analysis the only factor confirmed as affecting FFDBM was the GTV volume of the largest metastasis (table 1, supplementary files).This remained true if the sum of the GTVs in patients harboring several BM was considered. The estimated 1-year FFDBM rate between patients with homogeneous versus inhomogeneous dose prescription were $58 \%$ and $89 \%(p=0.002)$, respectively. The 1 -year FFDBM was $76 \%$ for patients with GTV volume $\leq 2.04$ compared to $55 \%$ in those having a GTV $>2.04 \mathrm{cc}$ ( $p=0.0001$ )(figure 3, supplementary files).

At last follow-up, $86(64 \%)$ patients were alive. The 1-year OS rate was $74 \pm 3.25 \%$. On univariate analysis, histology, DS-GPA, number of BM, presence of extra-cranial metastasis, dose distribution and tumor volume significantly influenced OS. On multivariate analysis the only factors confirmed as affecting OS were histology, DS-GPA and tumor volume (table 2, supplementary files). The estimated 1 -year OS rates between patients with homogeneous versus inhomogeneous dose prescription were $70 \%$ and $83 \%(p=0.01)$, respectively. At one year, $87 \%$ and $66 \%$ of patients with a low versus high DSGPA (cut-off 2.5) were still alive, respectively ( $p=0.001$ ) (figure 4 , supplementary files).

Acute toxicity was low: Grade 1 nausea and headaches were reported in 7 patients only (5.2\%): 5 of them (5.5\%) belonged to group 1 and $2(4.7 \%)$ to group 2 . No visual, motor or sensory deficits were recorded. PET-FET was performed in $20(22 \%)$ patients in group 1 and $3(7 \%)$ patients in group 2 . As diagnosed on PET-FET ( $n=10)$ and/or confirmed histologically $(n=8), 10$ patients developed RN, giving an overall 1-year RN rate of $6 \pm 2 \%$. All ten cases of RN occurred in group 1, yielding 1-year freedom from RN rates of $91 \%$ and $100 \%$ in group 1 and 2 , respectively $(p=0.02)$. Patients who had more than one BM also had a higher risk of developing RN. Both variables remained statistically significant on multivariate analysis (table 4). Patients with one versus $\geq 2 \mathrm{BM}$ had a 1-year freedom from RN of $97 \%$ and $90 \%$, respectively ( $p=0.01$ ) (figure 2 ). There was no influence of dosimetric parameters like V5Gy, V10Gy, V12Gy, or V21Gy on RN. Timing of systemic treatment did not correlate with the occurrence of RN either.

\section{DISCUSSION}

SRT requires well-defined target delineation, a highly conformal target dose distribution, steep dose fall-off beyond the target volume, precise patient setup, and accurate delivery of a high dose of radiation therapy [11]. A number of treatment techniques, including GammaKnife, CyberKnife, Linac with MLC, intensity-modulated radiosurgery (IMRS), intensity-modulated radiotherapy (IMRT), and helical tomotherapy have fulfilled these requirements for stereotactic treatments. All of these technologies use different dose prescription modalities [16], but the prescription's isodose is usually not reported in the literature. Moreover, the prescribed total dose varies considerably from one study to another, making comparison in terms of efficacy and toxicity difficult.

Whether dose heterogeneity is desirable when homogeneity with sufficient dose conformity can be achieved remains a matter of clinical debate. To our knowledge, this is the first study showing a difference in terms of LC between inhomogeneous versus homogeneous dose distribution. A likely explanation might be the effect of hypoxia on radiosensitivity. Indeed, the center of BM are often necrotic and data in head and neck cancer have shown that visible necrosis on pre-treatment imaging could be a surrogate marker for relevant radiobiological hypoxia [17]. As such, delivering a

higher dose to the hypoxic tumor cells could theoretically lead to improved LC. Although the near maximum dose did not remain significantly correlated with LC in multivariate analysis, the trend observed for a better LC with a higher D2\% in our study is consistent with this hypothesis. 
ICRU 83 previously recommended that the dose values in the PTV be confined within $95 \%$ to $107 \%$ of the PD when using IMRT [10]. However, SRT was historically delivered using dedicated devices like the GammaKnife and inhomogeneous dose distribution was standard. Given the significant experience and the excellent LC rate observed with this technique, a heterogeneous prescription still continues to be commonly used in the case of SRS and/or SRT even when using IMRT, especially in the treatment of $\mathrm{BM}[7,16,18]$. Therefore, the dose is currently often prescribed to the $60 \%$ to $80 \%$ isodose line (relative to maximum dose) which is located on the outerline of the PTV.

However, as highlighted in the ICRU report 91 on SRT, the disadvantage of this principle is the loss of the minimum or/and maximum dose reporting. Therefore, it is recommended, as in the ICRU Report 83 [10] that the extent of high and low dose be specified using dose-volume quantities such as SRT near-maximum dose (or D2\%) and the SRT near-minimum dose (or D98\%) for regions of high and low dose, respectively. Moreover, it is recommended that both the mean dose to the PTV and the standard deviation of the mean are reported.

Our LC rate of $85 \%$ at 1 year is similar to the one reported in literature $[19,20]$. Like others, we found a worse LC in patients with large lesions before SRT $[18,21]$. Indeed, tumor volume was the strongest predictive factor of LC in our cohort. Moreover, the RN rate is low as 1 year, as previously reported [22], and the number of metastases remains a risk factor of developing RN [23] . The V12Gy of the Brain has also been reported as a parameter linked to the risk factor of $R N$, but because we started SRT after the publication of these reports, we applied strict V12Gy constraints $[24,25]$.

We are aware that our analysis has several limitations. Firstly, our patients' population is heterogeneous with various primary tumors. As such, some patients received systemic treatments which could have impacted outcome, even though we couldn't identify any impact of the timing of systemic treatments on outcome, especially LC. Indeed, targeted therapies (Lapatinib, trastuzumabDM1, Afatinib, Alectinib...) can cross the blood-brain barrier [26, 27]. However, no statistically significant difference was found between the two groups in terms of primary tumor histology, HER-2 status, EGFR mutation, or ALK rearrangement. Secondly, toxicity is low but the follow-up is too short for any further consideration. Some authors also reported that, in this setting, the PD should be at least $40 \mathrm{~Gy}$ (with a $\mathrm{BED}_{12}$ ) corresponding to $8.5 \mathrm{~Gy}$ per fraction. Thus, the total dose we prescribe, although commonly used, might be seen as insufficient. However, this observation is based on 11 studies only, of which only 3 reported outcome after fractionated SRT [20]. Finally, the presence of unobserved confounding covariates may have contributed to the observed differences in LC and risk of RN between the two groups, especially the learning curve of the SRT implementation.

SRT delivered with inhomogeneous dose distribution resulted in better LC and lower RN rate compared to homogeneous dose distribution. FFDBM and OS were not significantly different. These results support the recommendations of the ICRU report 91 to use inhomogeneous dose distribution with a high dose in the middle of the target. 


\section{REFERENCES}

1. Mehta MP, Tsao MN, Whelan TJ et al. The American Society for Therapeutic Radiology and Oncology (ASTRO) evidence-based review of the role of radiosurgery for brain metastases. Int J Radiat Oncol Biol Phys 2005; 63: 37-46.

2. Ceci F, Castellucci P, Graziani T et al. 11C-choline PET/CT detects the site of relapse in the majority of prostate cancer patients showing biochemical recurrence after EBRT. Eur J Nucl Med Mol Imaging 2014; 41: 878-886.

3. Lin X, DeAngelis LM. Treatment of Brain Metastases. J Clin Oncol 2015; 33: 3475-3484.

4. Kocher $M$, Wittig $A$, Piroth $M D$ et al. Stereotactic radiosurgery for treatment of brain metastases. A report of the DEGRO Working Group on Stereotactic Radiotherapy. Strahlenther Onkol 2014; 190: 521-532.

5. Soffietti R, Kocher M, Abacioglu UM et al. A European Organisation for Research and Treatment of Cancer phase III trial of adjuvant whole-brain radiotherapy versus observation in patients with one to three brain metastases from solid tumors after surgical resection or radiosurgery: quality-of-life results. J Clin Oncol 2013; 31: 65-72.

6. Brown PD, Jaeckle K, Ballman KV et al. Effect of Radiosurgery Alone vs Radiosurgery With Whole Brain Radiation Therapy on Cognitive Function in Patients With 1 to 3 Brain Metastases: A Randomized Clinical Trial. JAMA 2016; 316: 401-409.

7. Alongi F, Fiorentino A, Mancosu $P$ et al. Stereotactic radiosurgery for intracranial metastases: linac-based and gamma-dedicated unit approach. Expert Rev Anticancer Ther 2016; 16: 731-740.

8. Fiorentino A, Levra NG, Mazzola R et al. Letter: Volumetric Arc Therapy (RapidArc) vs Gamma Knife Radiosurgery for Multiple Brain Metastases: Not Only a Dosimetric Issue. Neurosurgery 2015; 77: E310.

9. Fiorentino A, Giaj-Levra N, Mazzola $\mathrm{R}$ et al. Dosimetrics of intracranial stereotactic radiosurgery: Only "an exercise of style"? Strahlenther Onkol 2015; 191: 810-811.

10. Prescribing, Recording, and Reporting Intensity-Modulated Photon-Beam Therapy (IMRT)(ICRU Report 83). 2010.

11. ICRU Report 91, Prescribing, Recording, and Reporting of Stereotactic Treatments with Small Photon Beams. 2017.

12. Minniti G, D'Angelillo RM, Scaringi $C$ et al. Fractionated stereotactic radiosurgery for patients with brain metastases. J Neurooncol 2014; 117: 295-301.

13. Lin NU, Lee EQ, Aoyama $\mathrm{H}$ et al. Response assessment criteria for brain metastases: proposal from the RANO group. Lancet Oncol 2015; 16: e270-278.

14. Cicone F, Galldiks N, Minniti G et al. Comment on Hatzoglou et al: Dynamic contrastenhanced MRI perfusion versus 18FDG PET/CT in differentiating brain tumor progression from radiation injury. Neuro Oncol 2017; 19: 300-301.

15. Sperduto PW, Kased N, Roberge $D$ et al. Summary report on the graded prognostic assessment: an accurate and facile diagnosis-specific tool to estimate survival for patients with brain metastases. J Clin Oncol 2012; 30: 419-425.

16. Lippitz B, Lindquist C, Paddick I et al. Stereotactic radiosurgery in the treatment of brain metastases: the current evidence. Cancer Treat Rev 2014; 40: 48-59.

17. Dunst J, Stadler P, Becker A et al. Tumor volume and tumor hypoxia in head and neck cancers. The amount of the hypoxic volume is important. Strahlenther Onkol 2003; 179: 521-526.

18. Minniti G, Scaringi C, Paolini $S$ et al. Single-Fraction Versus Multifraction ( $3 \times 9$ Gy) Stereotactic Radiosurgery for Large $(>2 \mathrm{~cm})$ Brain Metastases: A Comparative Analysis of Local Control and Risk of Radiation-Induced Brain Necrosis. Int J Radiat Oncol Biol Phys 2016; 95: 11421148.

19. Soffietti R, Abacioglu U, Baumert B et al. Diagnosis and treatment of brain metastases from solid tumors: guidelines from the European Association of Neuro-Oncology (EANO). Neuro Oncol 2017; 19: 162-174. 
20. Wiggenraad R, Verbeek-de Kanter A, Kal HB et al. Dose-effect relation in stereotactic radiotherapy for brain metastases. A systematic review. Radiother Oncol 2011; 98: 292-297.

21. Vogelbaum MA, Angelov L, Lee SY et al. Local control of brain metastases by stereotactic radiosurgery in relation to dose to the tumor margin. J Neurosurg 2006; 104: 907-912.

22. Ernst-Stecken A, Ganslandt O, Lambrecht $U$ et al. Phase II trial of hypofractionated stereotactic radiotherapy for brain metastases: results and toxicity. Radiother Oncol 2006; 81: 18-24.

23. Miller JA, Bennett EE, Xiao R et al. Association Between Radiation Necrosis and Tumor Biology After Stereotactic Radiosurgery for Brain Metastasis. Int J Radiat Oncol Biol Phys 2016; 96: 1060-1069.

24. Blonigen BJ, Steinmetz RD, Levin $L$ et al. Irradiated volume as a predictor of brain radionecrosis after linear accelerator stereotactic radiosurgery. Int J Radiat Oncol Biol Phys 2010; 77: 996-1001.

25. Sahgal $A$, Ruschin $M, M a ~ L$ et al. Stereotactic radiosurgery alone for multiple brain metastases? A review of clinical and technical issues. Neuro Oncol 2017; 19: ii2-ii15.

26. Bai $H$, Xiong L, Han B. The effectiveness of EGFR-TKIs against brain metastases in EGFR mutation-positive non-small-cell lung cancer. Onco Targets Ther 2017; 10: 2335-2340.

27. Teng $\mathrm{F}$, Tsien $\mathrm{Cl}$, Lawrence TS, Cao Y. Blood-tumor barrier opening changes in brain metastases from pre to one-month post radiation therapy. Radiother Oncol 2017; 125: 89-93. 
Figure 1: probability of local control between (A) homogeneous dose vs inhomogeneous dose (B) low vs high volume

A.

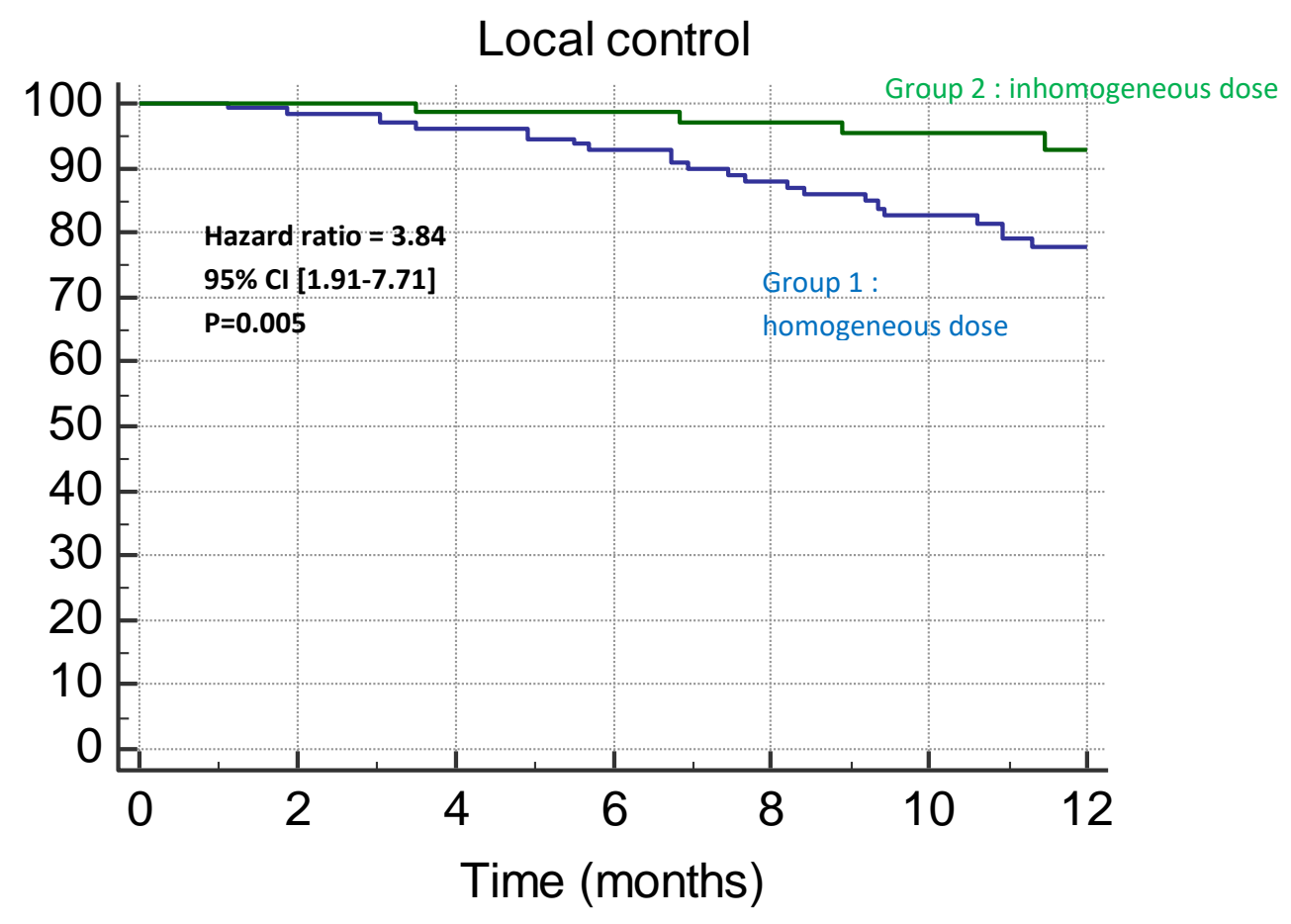

Number at risk

Group: 1

$\begin{array}{ccccccc}136 & 127 & 120 & 110 & 88 & 72 & 54 \\ \text { Group: } 2 & 72 & 71 & 71 & 64 & 41 & 31\end{array}$


B.

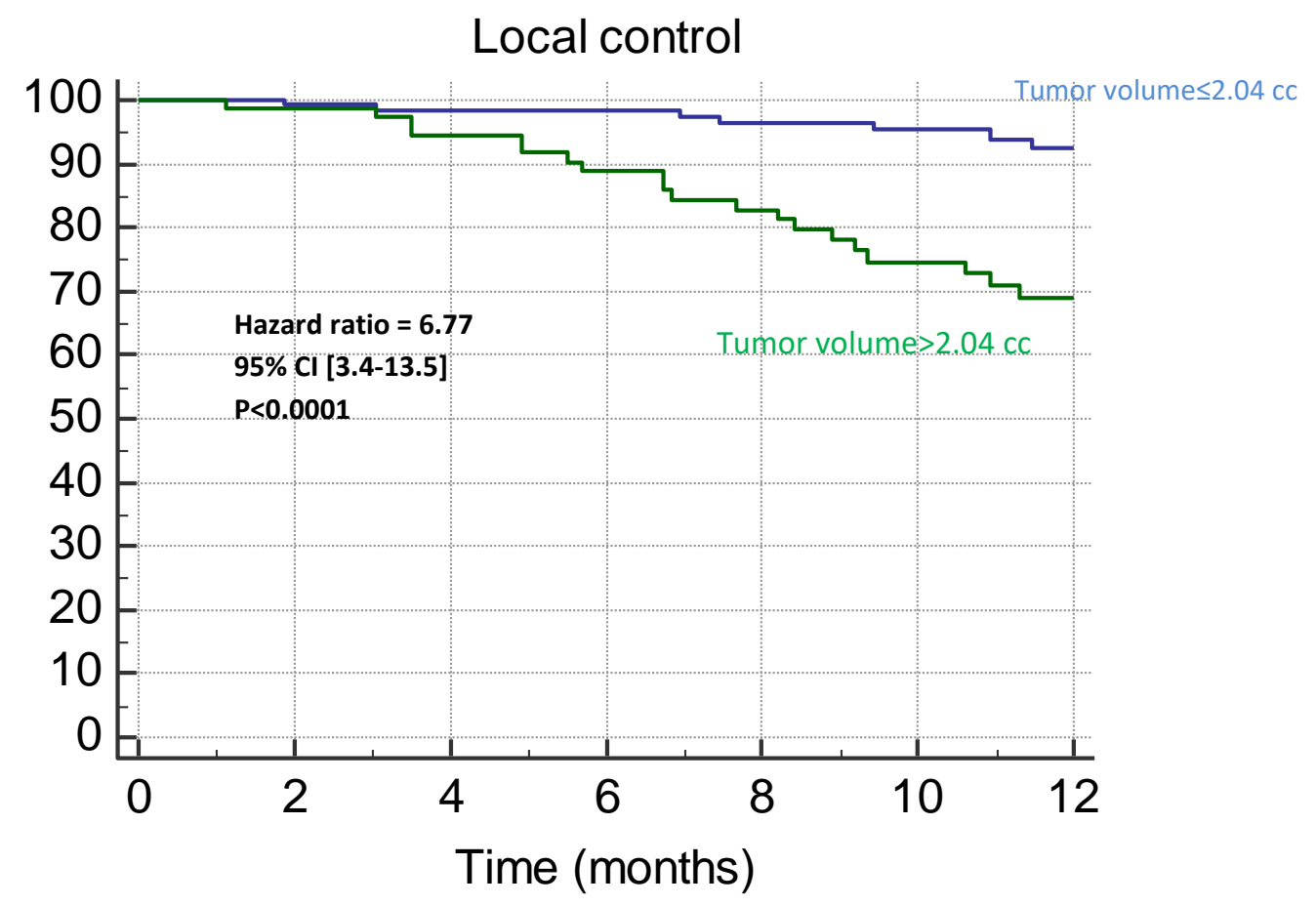

Number at risk

Group: Tumor volume $\leq 2.04 \mathrm{cc}$

$\begin{array}{lllllll}134 & 127 & 123 & 120 & 97 & 71 & 53\end{array}$

Group: Tumor volume $>2.04 \mathrm{cc}$

$\begin{array}{lllllll}74 & 72 & 68 & 61 & 55 & 42 & 32\end{array}$ 
Figure 2: probability of radionecrosis (RN) between (A) homogeneous dose vs inhomogeneous dose (B) 1 vs $>1$ metastases

A.

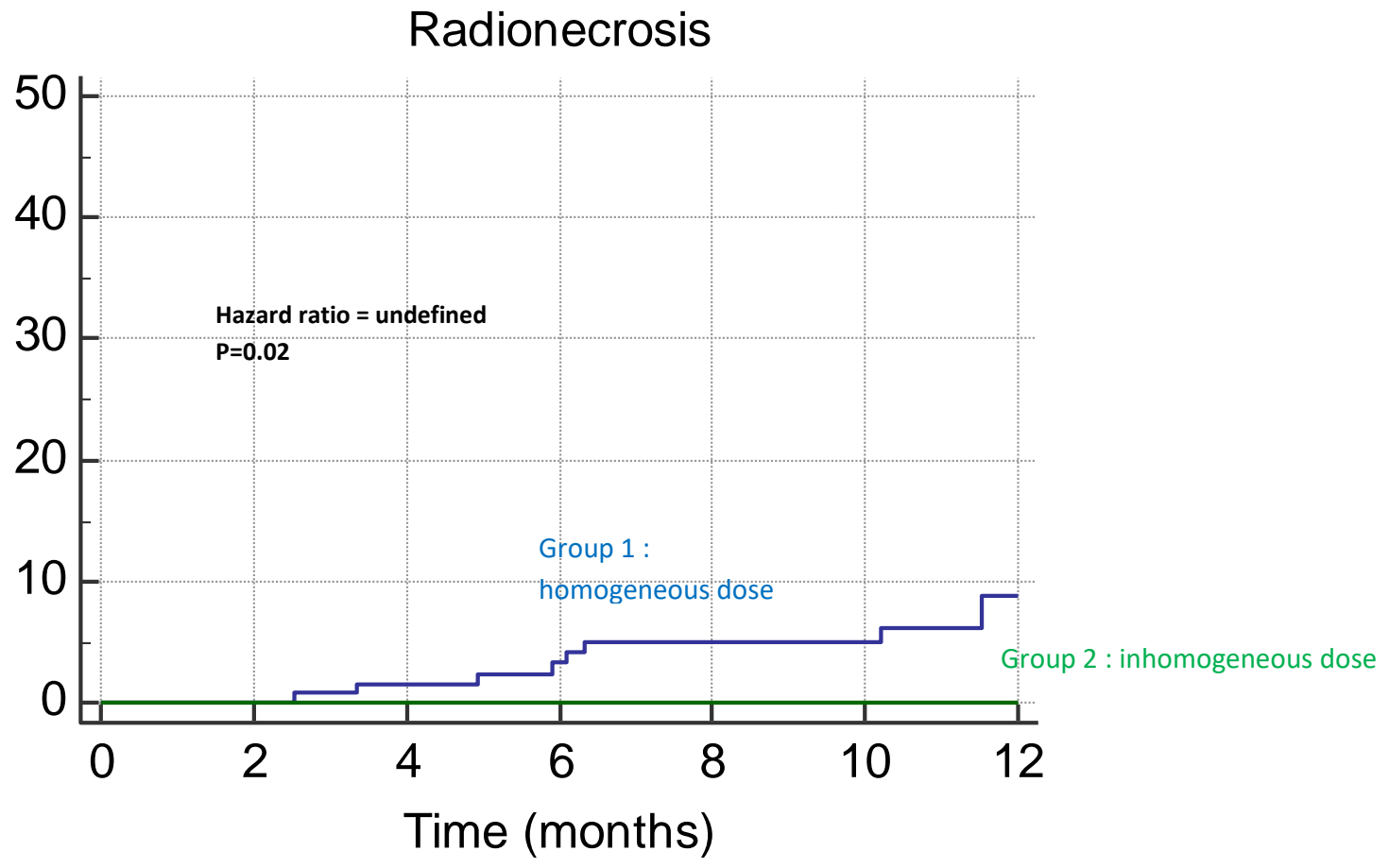

Number at risk

Group: 1

$\begin{array}{rrrrrrr}136 & 127 & 120 & 110 & 88 & 72 & 54 \\ \text { Group: } 2 & & & & & & \\ 72 & 72 & 71 & 71 & 64 & 41 & 31\end{array}$


B.

Radionecrosis

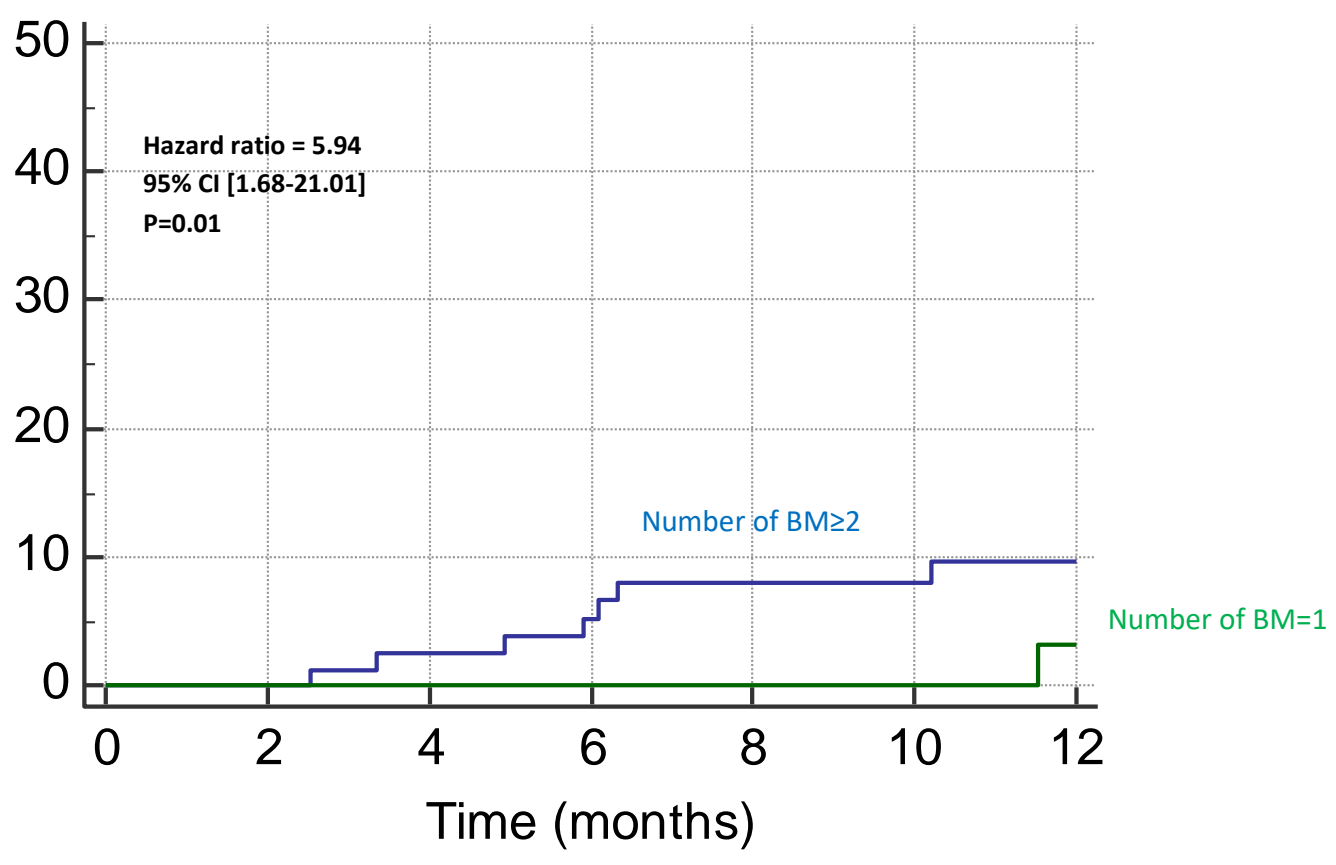

Number at risk

Group: Number of $\mathrm{BM} \geq 2$

$\begin{array}{lllllll}85 & 81 & 76 & 68 & 61 & 55 & 40\end{array}$

Group: Number of $\mathrm{BM}=1$

$\begin{array}{lllllll}123 & 119 & 119 & 116 & 96 & 69 & 51\end{array}$ 


\begin{tabular}{|c|c|c|c|c|c|}
\hline & \multicolumn{2}{|c|}{ Group 1} & \multicolumn{2}{|l|}{ Group 2} & \multirow{2}{*}{$\begin{array}{l}\text { Difference } \\
\text { (p-value) }\end{array}$} \\
\hline & $\mathrm{N}=91$ & $\%$ & $\mathrm{~N}=43$ & $\%$ & \\
\hline \multicolumn{6}{|l|}{ Gender } \\
\hline - Male & 54 & 59 & 26 & 60 & 0.94 \\
\hline - Female & 37 & 41 & 17 & 40 & \\
\hline Age median (range) & $62(26-86)$ & & $60(41-85)$ & & 0.89 \\
\hline \multicolumn{6}{|l|}{ Prior WBRT } \\
\hline - Yes & 9 & 10 & 5 & 12 & 0.96 \\
\hline - No & 82 & 90 & 38 & 88 & \\
\hline \multicolumn{6}{|l|}{ Primary } \\
\hline - Breast & 12 & 13 & 6 & 14 & 0.91 \\
\hline O HER-2 + & $10 / 134$ & 7.5 & $4 / 72$ & 5.6 & 0.95 \\
\hline - Lung & 61 & 67 & 27 & 63 & 0.79 \\
\hline$\circ$ EGFR+ & $4 / 134$ & 3 & $3 / 72$ & 4.1 & 0.83 \\
\hline - ALK+ & $8 / 134$ & 6 & $4 / 72$ & 5.6 & 0.87 \\
\hline O EGFR -/ALK- & $122 / 134$ & 91 & $65 / 72$ & 90.3 & 0.89 \\
\hline - Melanoma & 9 & 10 & 6 & 14 & 0.7 \\
\hline - Renal & 4 & 4 & 1 & 2 & 0.93 \\
\hline - $\mathrm{Gl}$ & 5 & 6 & 2 & 5 & 0.87 \\
\hline Number of BMs median (range) & $2(1-6)$ & & $2(1-5)$ & & 0.81 \\
\hline \multicolumn{6}{|l|}{ Tumor size $(\mathrm{cm})$} \\
\hline$\bullet<2$ & $74 / 134$ & 55.2 & $39 / 72$ & 54.2 & 0.94 \\
\hline - $2-3$ & $34 / 134$ & 25.4 & $18 / 72$ & 25 & 0.83 \\
\hline - $\quad>3$ & $26 / 134$ & 19.4 & $15 / 72$ & 20.8 & 0.97 \\
\hline GTV volume (cc) & $1.4(0.05-33.2)$ & & $1.73(0.05-26.9)$ & & 0.73 \\
\hline PTV volume (cc) & $3.5(0.4-43.3)$ & & $3.9(0.4-39.2)$ & & 0.77 \\
\hline \multicolumn{6}{|l|}{ Extra cranial metastases } \\
\hline - Yes & 32 & 35.1 & 16 & 37.2 & 0.97 \\
\hline - No & 59 & 64.9 & 27 & 62.8 & \\
\hline DS-GPA score median (range) & $3(1-4)$ & & $2.5(1-4)$ & & 0.63 \\
\hline KPS median (range) & $90(60-100)$ & & $90(60-100)$ & & 0.71 \\
\hline \multicolumn{6}{|l|}{ RPA class } \\
\hline$\bullet \quad 1$ & $10 / 91$ & 11 & $5 / 43$ & 11.7 & 0.9 \\
\hline - II & $80 / 91$ & 87.9 & $37 / 43$ & 86 & 0.96 \\
\hline - III & $1 / 91$ & 1.1 & $1 / 43$ & 2.3 & 0.74 \\
\hline \multicolumn{6}{|l|}{ Neurologic symptoms } \\
\hline - None & 29/91 & 31.9 & $13 / 43$ & 30.3 & 0.97 \\
\hline - Mild & $44 / 91$ & 48.4 & $21 / 43$ & 48.8 & 0.94 \\
\hline - Moderate & $16 / 91$ & 17.6 & $8 / 43$ & 18.6 & 0.97 \\
\hline - Severe & $2 / 91$ & 2.1 & $1 / 43$ & 2.3 & 0.51 \\
\hline
\end{tabular}


Systemic Treatment

- Prior

$89(134)$

$98(99) \quad 41(70)$

95 (97)

0.68

- Concurrently

$11(24)$

$12(18) \quad 5(13)$

$12(18)$

0.78

- After

72 (113)

$79(83) \quad 34(59)$

$79(82)$

0.82

Abbreviations: WBRT=Whole Brain Radiation Therapy, HER-2=Human Epidermal Growth Factor Receptor 2, EGFR=Epithelial Growth Factor Receptor, ALK=activin-like kinase, GI=Gastro-Intestinal, BM=Brain Metastases, DS-GPA=Diagnostic-Specific Graded Prognostic Assessment, KPS=Karnofsky Performance Status, RPA=Recursive partitioning analysis 


\begin{tabular}{|c|c|c|c|c|c|}
\hline & Group 1 & & Group 2 & & Difference \\
\hline & $\begin{array}{c}\mathrm{N}=91 \\
\text { Median (range) }\end{array}$ & $\%$ & $\begin{array}{c}\mathrm{N}=43 \\
\text { Median (range) }\end{array}$ & $\%$ & \\
\hline$D_{98 \%}$ & $23.1 \mathrm{~Gy}(21-23.1)$ & & 23.3 Gy (21-23.8) & & 0.41 \\
\hline$D_{2 \%}$ & $24.8(22.5-25.2)$ & & $32.9(29.8-33.2)$ & & $<0.0001$ \\
\hline$D_{50 \%}$ & $24.2(21.2-25.4)$ & & $28.1(27.7-29.8)$ & & $<0.0001$ \\
\hline$V_{5 G y \text { (brain) }}$ & $105.9(43.2-184.8)$ & & $104.3(42.4-172.5)$ & & 0.15 \\
\hline$V_{10 G y(\text { brain) }}$ & $9.63(4.83-29.1)$ & & $9.07(4.42-24.51)$ & & 0.18 \\
\hline $\mathrm{V}_{12 \mathrm{~Gy} \text { (brain) }}$ & $3.22(0.45-9.31)$ & & $2.71(0.15-6.21)$ & & 0.08 \\
\hline$V_{21 G y \text { (brain) }}$ & $0.83(0-2.42)$ & & $0.79(0-2.31)$ & & 0.43 \\
\hline Target coverage & $99.0(95.4-100)$ & & $98.9(95.3-100)$ & & 0.84 \\
\hline Conformity Index & $1.33(1.05-1.62)$ & & $1.32(1.06-1.61)$ & & 0.87 \\
\hline SRT dose & & & & & \\
\hline - $23.1 \mathrm{~Gy}$ in 3 fractions & $101 / 136$ & 81.7 & $59 / 72$ & 81.9 & 0.81 \\
\hline - 21 Gy in 3 fractions & $25 / 136$ & 18.3 & $13 / 72$ & 18.1 & \\
\hline
\end{tabular}

Abbreviations: GTV=Gross Tumor Volume, PTV=Planning Target Volume, $D_{98 \%}=$ dose to $98 \%$ of the $\mathrm{PTV}=$ the near minimum dose, $\mathrm{D}_{2 \%}=$ dose to $2 \%$ of the $\mathrm{PTV}=$ the near maximum dose, $\mathrm{D}_{50 \%}=$ dose to $50 \%$ of the PTV $=$ The median absorbed dose, $\mathrm{V}_{12 G \mathrm{y} \text { (brain) }}=$ volume of brain receiving dose larger than or equal to $12 \mathrm{~Gy}$, SRT=Stereotactic Radiation Therapy 
Table 3: Univariate and multivariate analysis for local control (LC)

\begin{tabular}{|c|c|c|c|c|c|c|}
\hline \multirow[t]{2}{*}{ Variables } & \multicolumn{3}{|c|}{ Univariate analysis } & \multicolumn{3}{|c|}{ Multivariate analysis } \\
\hline & $\mathrm{HR}$ & $95 \% \mathrm{Cl}$ & $p$ & HR & $95 \% \mathrm{Cl}$ & $p$ \\
\hline Histology (breast vs. others ) & 0.57 & $0.28-1.22$ & 0.10 & - & - & - \\
\hline Age (>57 vs. $\leq 57)$ & 2.14 & $0.78-4.69$ & 0.09 & - & - & - \\
\hline Gender (Male vs. Female) & 1.38 & $0.69-2.79$ & 0.26 & - & - & - \\
\hline DS-GPA ( <2.5 vs. $\geq 2.5$ ) & 1.61 & $0.84-3.11$ & 0.17 & - & - & - \\
\hline RPA (| vs. >|) & 1.45 & $0.74-2.82$ & 0.25 & - & - & - \\
\hline Number of BM (>1 vs. 1) & 1.46 & $0.75-2.84$ & 0.25 & - & - & - \\
\hline ECM (yes vs. no) & 1.18 & $0.59-2.38$ & 0.63 & - & - & - \\
\hline KPS (<90 vs. $\geq 90)$ & 1.47 & $0.76-2.86$ & 0.24 & & & \\
\hline GTV volume (>2.04 vs. $\leq 2.04$ ) & 6.77 & $3.40-13.50$ & $<0.0001$ & 1.04 & $1.01-1.11$ & 0.03 \\
\hline PTV volume (>4.18 vs. $\leq 4.18$ ) & 5.75 & $2.89-11.44$ & $<0.0001$ & - & - & - \\
\hline Size (>13mm vs. $\leq 13 \mathrm{~mm})$ & 1.57 & $0.79-3.13$ & 0.17 & - & - & - \\
\hline Dose distribution (HG vs. INH) & 3.84 & $1.91-7.71$ & 0.005 & 1.71 & $1.52-2.03$ & 0.009 \\
\hline $\mathrm{D}_{2 \%}(<30.2 \mathrm{~Gy} v s . \geq 30.2 \mathrm{~Gy})$ & 3.17 & $1.57-6.81$ & 0.009 & 1.02 & $0.91-1.07$ & 0.18 \\
\hline $\mathrm{D}_{50 \%}(<28.0 v s . \geq 28.0 \mathrm{~Gy})$ & 2.35 & $0.89-5.34$ & 0.07 & - & - & - \\
\hline Dose (21Gy vs. 23.1Gy) & 1.22 & $0.47-3.20$ & 0.70 & - & - & - \\
\hline ST prior (yes vs.no) & 0.92 & $0.14-6.34$ & 0.94 & - & - & - \\
\hline ST concurrently (yes vs.no) & 0.95 & $0.41-2.20$ & 0.90 & - & - & - \\
\hline ST after (yes vs.no) & 0.58 & $0.25-1.35$ & 0.14 & - & - & - \\
\hline
\end{tabular}

Abbreviations: $\mathrm{HR}=$ hazard ratio, $\mathrm{Cl}=$ confidence interval, DS-GPA=Diagnostic-Specific Graded Prognostic Assessment, RPA=Recursive partitioning analysis, BM=Brain Metastases, ECM= Extra cranial metastases, KPS=Karnofsky Performance Status, GTV=Gross Tumor Volume, PTV=Planning Target Volume, HG=Homogeneous, INH=Inhomogeneous, ST= Systemic Treatment. 
Table 4: Univariate and multivariate analysis for radionecrosis (RN)

\begin{tabular}{|c|c|c|c|c|c|c|}
\hline \multirow[t]{2}{*}{ Variables } & \multicolumn{3}{|c|}{ Univariate analysis } & \multicolumn{3}{|c|}{ Multivariate analysis } \\
\hline & $\mathrm{HR}$ & $95 \% \mathrm{Cl}$ & $p$ & $\mathrm{HR}$ & $95 \% \mathrm{Cl}$ & $p$ \\
\hline Histology (breast vs. others) & 0.96 & $0.10-8.83$ & 0.94 & - & - & - \\
\hline Age (>57 vs. $\leq 57)$ & 1.57 & $0.40-6.23$ & 0.56 & - & - & - \\
\hline Gender (Male vs. Female) & 0.58 & $0.16-2.11$ & 0.39 & - & - & - \\
\hline DS-GPA (<2.5 vs. $\geq 2.5)$ & 3.64 & $1.05-12.58$ & 0.08 & - & - & - \\
\hline RPA (| vs. > I) & 3.31 & $0.83-10.67$ & 0.1 & - & - & - \\
\hline Number of BM (>1 vs. 1) & 5.94 & $1.68-21.01$ & 0.01 & 1.17 & $1.07-1.27$ & 0.03 \\
\hline ECM (yes vs. no) & 1.04 & $0.29-3.70$ & 0.95 & - & - & - \\
\hline KPS (<90 vs. $\geq 90)$ & 3.52 & $0.93-11.71$ & 0.09 & - & - & - \\
\hline GTV volume (>2.04 vs. $\leq 2.04$ ) & 2.58 & $0.71-9.31$ & 0.13 & - & - & - \\
\hline PTV volume (>4.18 vs. $\leq 4.18)$ & 2.58 & $0.71-9.31$ & 0.13 & - & - & - \\
\hline Size (>13mm vs. $\leq 13 \mathrm{~mm})$ & 3.75 & $1.09-12.96$ & 0.07 & - & - & - \\
\hline Dose distribution (HG vs. INH) & & & 0.02 & 1.14 & $1.03-1.22$ & 0.04 \\
\hline Dose (21Gy vs. 23.1Gy) & 0.7 & $0.12-4.21$ & 0.73 & - & - & - \\
\hline$V_{5 G y}(>98.9 v s . \leq 98.9)$ & 2.51 & $0.65-9.11$ & 0.14 & - & - & - \\
\hline $\mathrm{V}_{10 \mathrm{~Gy}}(>15.5$ vs. $\leq 15.5)$ & 2.57 & $0.70-9.27$ & 0.13 & - & - & - \\
\hline $\mathrm{V}_{12 \mathrm{~Gy}}(>3.8 v s . \leq 3.8)$ & 2.49 & $0.62-8.93$ & 0.15 & - & - & - \\
\hline $\mathrm{V}_{21 \mathrm{~Gy}}(>1.42$ vs. $\leq 1.42)$ & 2.37 & $0.54-8.65$ & 0.17 & - & - & - \\
\hline ST prior (yes vs.no) & 0.22 & $0.04-13.01$ & 0.11 & - & - & - \\
\hline ST concurrently (yes vs.no) & 0.78 & $0.15-4.19$ & 0.76 & - & - & - \\
\hline ST after (yes vs.no) & 0.92 & $0.19-4.51$ & 0.92 & - & - & - \\
\hline
\end{tabular}

Abbreviations: $\mathrm{HR}=$ hazard ratio, $\mathrm{Cl}=$ confidence interval, DS-GPA=Diagnostic-Specific Graded Prognostic Assessment, RPA=Recursive partitioning analysis, BM=Brain Metastases, ECM= Extra cranial metastases, KPS=Karnofsky Performance Status, GTV=Gross Tumor Volume, PTV=Planning Target Volume, HG=Homogeneous, INH=Inhomogeneous, ST= Systemic Treatment. 